\title{
EVOLUÇÃO MORFOLÓGICA NO CORREDOR FLUVIAL DO RIO PARAGUAi ENTRE A BAÍA DA PALHA E O SADAO EM CÁCERES-MT
}

\author{
José Lourenço Alves da Silva ${ }^{(a)}$, Célia Alves de Souza ${ }^{(b)}$ \\ ${ }^{\text {(a) }}$ Mestrando em Geografia pela Universidade do Estado de Mato Grosso PPGGEO -UNEMAT- \\ jose.geo.alves@hotmail.com

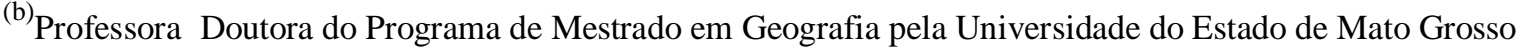 \\ PPGGEO-UNEMAT-celiaalvesgeo@globo.com
}

\section{EIXO: BACIAS HIDROGRÁFICAS E RECURSOS HÍDRICOS: ANÁLISE, PLANEJAMENTO E GESTÃO}

\begin{abstract}
Resumo
O estudo teve por objetivo avaliar a evolução de feições morfológicas ocorridas no corredor fluvial do rio Paraguai entre a Baía da Palha e a baía do Sadao no período de 1975 a 2016. Foram realizados trabalhos de caráter bibliográfico, foi confeccionado um mapa de evolução da planície através da ferramenta ArcGis 10.2.1, foram escolhidas dois períodos distintos, 1975 e 2016. As feições que corresponderam ao ano de 1975, foram vetorizadas a partir da carta topográfica do Exército brasileiro, e as feições que se referem se ao ano de 2016 foram vetorizadas a partir da imagem de Satélite Landsat 8 OLI. A análise espaço-temporal demonstrou que o trecho estudado sofreu mudanças em suas características morfológicas ao longo desses 41 anos: 03 lagoas e 01 baía evoluíram para canais secundários, surgiram 03 novas lagoas, 01 nova baía e 06 barras de sedimentos.
\end{abstract}

Palavras chaves: Canais Fluviais, Sedimentação, Migração de Canais.

\section{INTRODUÇÃO}

O Pantanal Mato-grossense é considerado a maior planície alagada do planeta. $\mathrm{Na}$ atualidade tem sofrido diversos tipos de alterações em seu ciclo hidrológico e ecológico, através de fatores naturais e antrópicos, como os diferentes tipos de uso (cultivo, pecuária e navegação). Dessa forma, quaisquer alterações nas variáveis que envolvem o Pantanal Mato-grossense (relevo, clima, solo, vegetação) podem afetar sua dinâmica, principalmente, no que se refere ao ciclo hidrológico das águas (CLARKE; TUCCI; COLLIISHONN, 2003).

Segundo Souza (2004 p. 6) o rio Paraguai é um dos mais importantes do Brasil, “o rio principal e seus afluentes percorrem grandes extensões em planícies e pantanais mato-grossenses, contribuindo para a manutenção das características locais do pantanal”, transporta e recebe, além de água, um grande aporte de sedimentos e nutrientes. 
Em particular, rios de planícies tem seu equilíbrio natural desestabilizado quando recebem os efeitos das atividades antrópicas, Rocha (2011) ressalta que, quando a planície de inundação é afetada, modifica-se toda a dinâmica dos processos erosivos e deposicionais, a consequência é o abandono de canais, geração e destruição de ilhas, e migração de canais.

No que diz respeito à dinâmica fluvial de rios, o processo de sedimentação ocorre por erosão e transporte de sedimentos, nos rios de padrão meandrante a erosão ocorre nas margens côncavas, em seguida os sedimentos são depositados na margem convexa (SUGUIO e BIGARELA 1990). Ou seja, a morfologia dos canais, é alterada pela ação hidráulica das águas correntes. Para Christofoletti (1981), após os sedimentos serem retirados pela erosão, é depositado exatamente, no mesmo lado da mesma margem a jusante, formando diferentes feições ao longo da planície de inundação.

Os processos de erosão e sedimentação ocorrem de forma natural, em sua maioria, em todos os tipos de canais fluviais. A água é o principal agente modelador do canal, bem como, para o surgimento de novas geoformas nos respectivos ambientes de atuação, como os sistemas fluviais. Para Silva (2012), ao se referir ao rio Paraguai, relatam que a gênese da carga de sedimentos está relacionada com a própria dinâmica fluvial.

Souza (2004) define que os canais fluviais migram através das inúmeras mudanças morfológicas resultantes de sua dinâmica, respectivamente, avançam para as planícies de inundação. A decorrência desse processo é o surgimento de braços, lagoas, baías e canais secundários (furados).

No Brasil foram realizados diversos trabalhos em ambientes fluviais onde o comportamento hidrodinâmico e sedimentológicos. No rio Paraná Santos et.al (1992) analisou os aspectos morfológicos evolutivos de barras de sedimentos, como: barras laterais, centrais e de soldamento. No rio Paraguai, Souza (2004) identificou diferentes alterações morfológicas no rio Paraguai ocasionados pela dinâmica fluvial, da cidade de Cáceres até a Reserva Ecológica da Ilha Taiamã. Bühler (2011) monitorou a qualidade da água e aspectos sedimentológicos da Baía do Iate até a região da Baía do Sadao. Silva et.al (2012) evidenciou evolução nas feições morfológicas na planície de inundação e o processo de sedimentação do trecho do Furado do Touro até a Passagem Velha. Bindade (2014) identificou que a evolução das navegações no rio Paraguai contribuiu para as mudanças morfológicas através do aumento na produção de sedimentos promovidos pelo fluxo de motores das embarcações no corredor fluvial do rio Paraguai.

Os processos fundamentais de sedimentação nas planícies aluviais de rios meandrantes são a deposição por acréscimo vertical e a deposição por acréscimo lateral, como nos modelos estabelecidos por Allen (1964) e Leopold e Wolman (1960). Os depósitos de acréscimo vertical incluem os sedimentos depositados nas planícies nas épocas dos transbordamentos (floodplain deposits) junto às margens fluviais 
(depósitos proximais), como os diques marginais (levee deposits) e os depósitos de rompimento de diques (crevasse splay deposits); e aqueles que se depositam no interior da planície (depósitos distais), como nas bacias de decantação ou pântanos (backswamp). Os depósitos de acréscimo lateral são formados nas margens do canal fluvial pela atividade do fluxo, onde os sedimentos são dispostos, frequentemente, em barras inclinadas, originados pela migração lateral do canal, como os cordões marginais convexos (point bars) e os depósitos residuais ou de defasagem (channel lag deposits).

As alterações na morfologia dos canais têm provocado grandes perdas socioeconômicas: assoreamento do leito, afeta a navegação, pode promover perdas de áreas de cultivo, de rodovias e pontes. Estabelecidos nas áreas de corredor fluvial são impactadas pela ação das águas (SOUZA, 2004; SILVA et.al 2011).

Contudo, o presente estudo teve por objetivo analisar a evolução de feições morfológicas ocorridas no corredor fluvial do rio Paraguai no trecho entre a baía da Palha e a baía do Sadao, no município de Cáceres-MT.

\section{MATERIAL E MÉTODOS}

\section{1 Área de estudo}

A área de estudo corresponde ao corredor fluvial do rio Paraguai entre a baía da Palha e a baía do Sadao no trecho de expansão urbana de Cáceres, Mato Grosso. Localiza-se entre as coordenadas

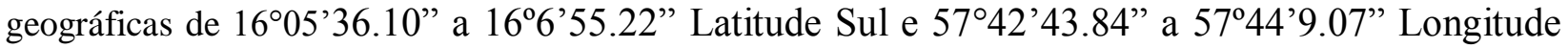
Oeste (figura 1). 


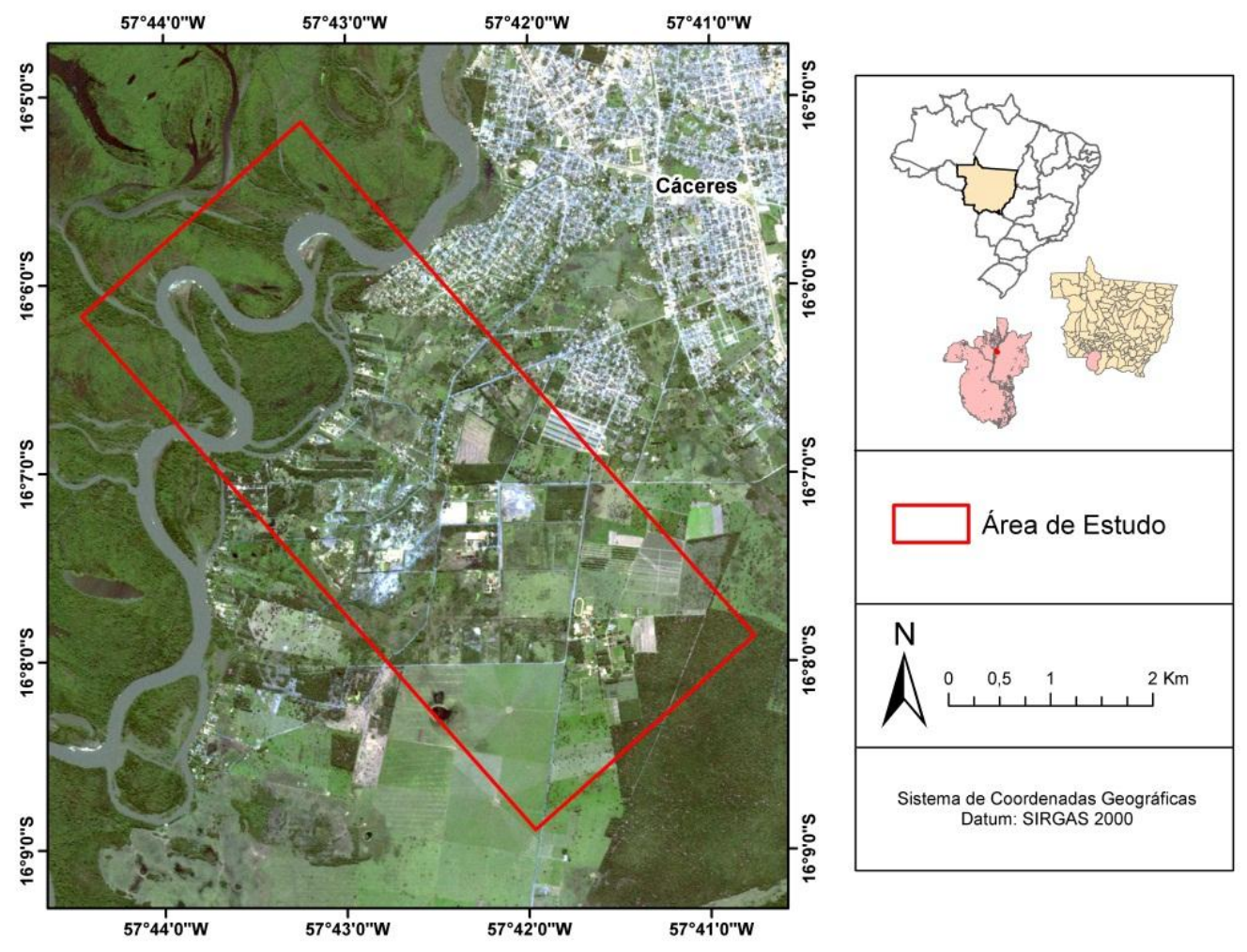

Figura 1 - Corredor fluvial do rio Paraguai entre a baía da Palha e a baía do Sadao.

\subsection{Procedimentos metodológicos}

O tratamento e a organizações dos dados qualitativos e quantitativos, bem como a elaboração de mapas e tabela foi efetuado em gabinete. Também foi realizado o trabalho de caráter bibliográfico, que constituiu de levantamentos de materiais elaborados principalmente por livros, teses, dissertações e artigos de cunho científico. Uma etapa importante para a construção de um arcabouço teórico conceitual e exploratório, porém não exaustivo, que propiciou em uma análise das diversas posições acerca da problemática em questão.

As feições que corresponderam ao ano de 1975, foram vetorizadas a partir da carta topográfica do Exército brasileiro, e as feições que se referem se ao ano de 2016 foi vetorizada a partir da imagem de Satélite Landsat 8 OLI. Para o processo de georreferenciamento, segmentação e classificação foi utilizado o software de mapeamento digital Spring 5.2.7 (OpenSource) disponível gratuitamente no site do INPE (Instituto Nacional de pesquisas Espaciais) e ArcGis 10.2.1. Portanto, o mapeamento espaço-temporal foi 
analisado e comparado em dois períodos distintos (1975 e 2016), para verificar a evolução da planície do rio Paraguai no intervalo de 41 anos.

\section{RESULTADOS E DISCUSSÕES}

\subsection{Caracterização Geoambiental}

A área de estudo encontra-se na unidade geomorfológica planície do rio Paraguai sendo uma área inundável ou sujeita a inundação. Sendo constituída por depósitos sedimentares que ainda estão em processos de sedimentação, com presença de aluviões atuais e/ou holocênicos.

A planície de inundação é uma área plana resultante de acumulação fluvial que é periodicamente alagada durante os picos de cheia do rio Paraguai. A baixa declividade, atributo típico de planície inundável. Para Souza et al. (2012), o nível da água do rio Paraguai eleva-se durante o período de cheia, transbordando para os canais secundários, baías, lagoas ou nas planícies marginais, provocando a remoção e a remobilização de sedimentos nesses ambientes.

O trecho possui morfologia peculiar com feições positivas e negativas. As feições positivas correspondem aos diques marginais, cordões marginais e barras laterais e centrais. As feições negativas correspondem às baías e lagoas.

As barras de sedimentos encontram-se geralmente nas laterais do canal ou emersa no meio do canal, suas formas e dimensões são variadas. Os diques são depósitos de transbordamentos e de rompimentos encontrados na planície de inundação. Os cordões são depósitos de transbordamento, suas origens estão relacionadas aos sucessivos períodos de cheia e vazante.

As lagoas são consideradas áreas deprimidas, circulares e não conectadas ao canal principal, sua quantidade de água oscila no período de cheia e estiagem, dependem do lençol freático para sua manutenção. As baías são definidas como áreas deprimidas, circulares e semicirculares, possui conexão com canal principal, recebendo uma quantidade de água e sedimentação no período de cheia, sua origem está associada ao rompimento do colo do meandro.

Quanto a litologia registra a ocorrência dos aluviões. Correspondem aos materiais inconsolidados que se encontram, em deposição nas planícies fluviais. A origem dos depósitos aluviais relaciona-se à dinâmica dos períodos de cheia do rio Paraguai, quando transbordam águas e sedimentos, depositando-os na planície de inundação..

Para Barros et al. (1982), o processo de deposição sedimentar pode ocorrer através dos depósitos de canal, barra, em pontal e transbordamento. A variação na composição do material depositado pode ser 
de areias, silte, argila e cascalho, reconhecendo-se que as camadas depositadas possuem pequena espessura, não atingindo 10 metros.

No segmento de estudo se predomina a ocorrência do tipo Gleissolos Háplico Tb Eutrófico. O Gleissolo Háplico Tb Eutrófico é caracterizado por apresentar forte gleização em virtude do regime de umidade redutor que se forma nos meios anaeróbicos originados de encharcamentos periódicos ou constantes. Apresenta sequência de horizontes do tipo A, Cg, com ou sem descontinuidade litológica, sendo o horizonte A do tipo moderado. A sua ocorrência se limita as áreas deprimidas sujeitas às inundações e às margens de curso de água, relacionados a sedimentos recentes do período Quaternário (OLIVEIRA et al.1982).

\subsection{Evolução das feições morfológicas espaço-temporal}

O estudo foi realizado no corredor fluvial do rio Paraguai. Nesse trecho o rio possui o padrão meandrante, com várias feições tais como: canais secundários, baías, lagoas, diques, cordões marginais e barras de sedimentos.

Em 1975 registrou a ocorrência de cinco baías e três lagoas. Em 2016 registrou diversas alterações no corredor fluvial como surgimento e desaparecimento de feições, conexão de feições, aumento e diminuição de áreas das feições. A lagoa (L1) foi ampliada evoluindo para novo canal secundário (NC1). As lagoas (L1, L2, L3) e baía (B5) uniram formando os novos canais secundários (NC2 e NC3). Surgiram três novas lagoas (NL1, NL2 e NL3), uma nova baía (NB1) e o surgimento de seis barras de sedimentos (BS01, BS02, BS03, BS04, BS05, BS06) (figura 2 e tabela 1).

Ao comparar as baías B01, B02, e B04, no ano de 2016 em relação ao ano de 1975, nota se que houve a diminuição da dimensão das baías, somente a B03 aumentou expressivamente de tamanho. A grande quantidade de sedimentação pode ter contribuído para a redução das baías que podem estar relacionados ao assoreamento que ocorre nas relacionada ao ciclo de cheia e estiagem, através da deposição de sedimentos, que são transportados pelo rio Paraguai (figura 2 Tabela 1).

Essas alterações estão relacionadas á própria dinâmica fluvial associada a fatores como: padrão do canal, regime hídrico, declividade, estrutura litológica e tipos de solos (material de margens). As imagens apresentam duas evoluções do colo do meandro. Porém o canal novo 01 (NC 01) na sua entrada foi efetuado o aprofundamento calha para aumentar o volume de água e para viabilizar o acesso via fluvial o ano todo. 
XVII Simpósio Brasileiro

de Geografia Fisica Aplicada

I Congresso Nacional

de Geografia Física
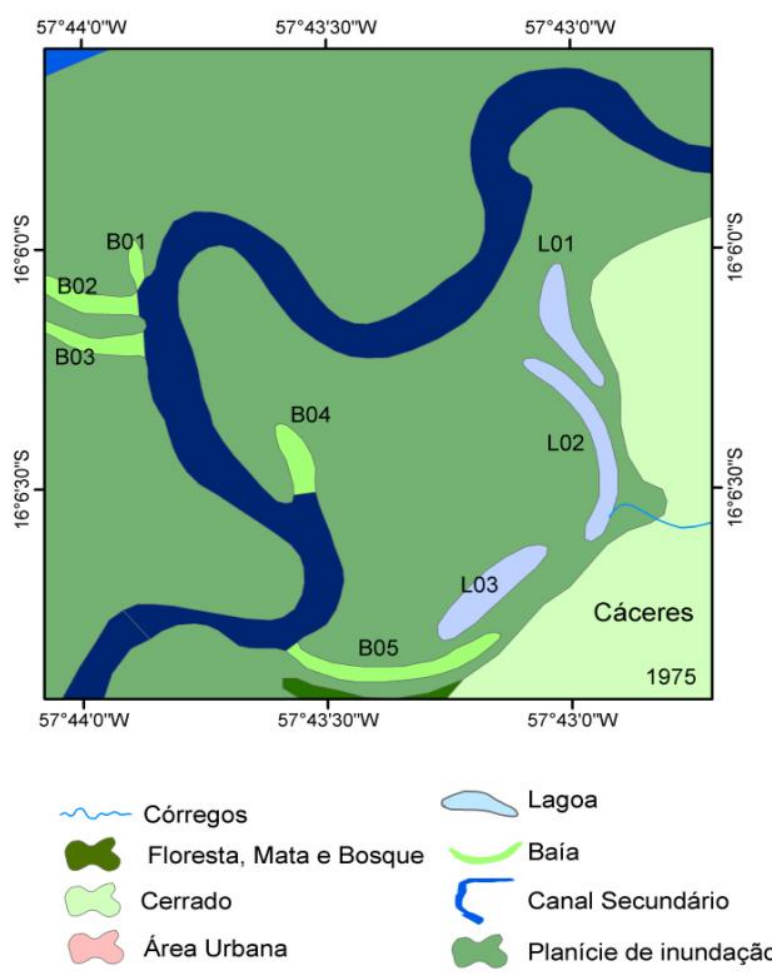

OS DESAFIOS DA GEOGRAFIA FÍSICA NA FRONTEIRA DO CONHECIMENTO

Instituto de Geociências - Unicamp

Campinas - SP

28 de Junho à 02 de Julho de 2017

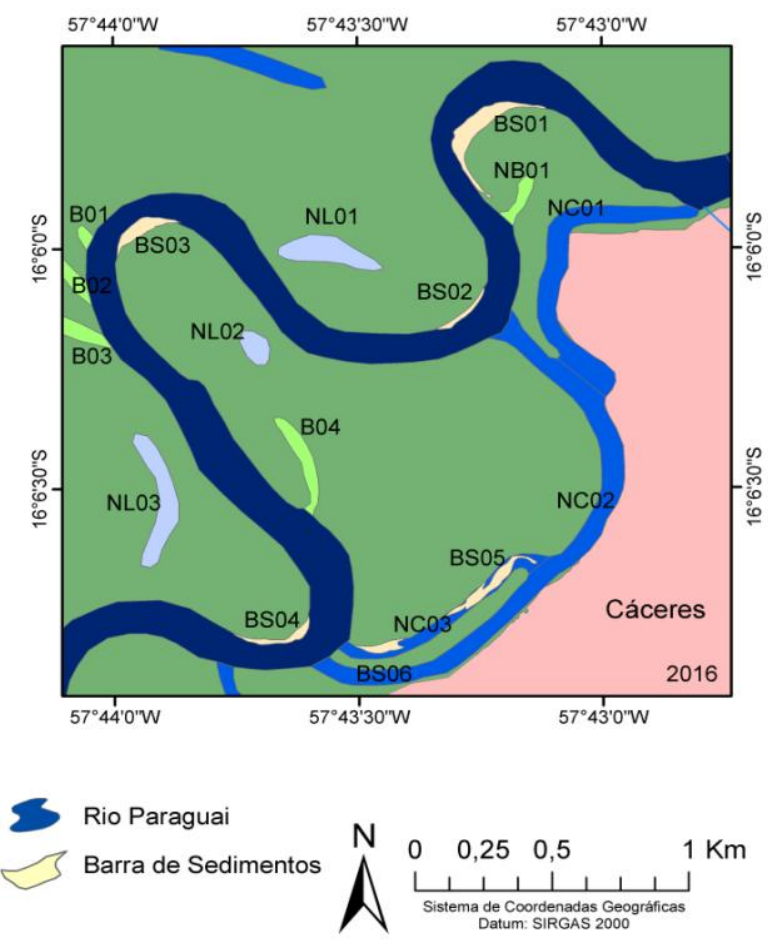

Figura 2 - Evolução de feições morfológicas espaço-temporal no corredor fluvial do rio Paraguai.

Em 2016 foi mapeado, no leito do rio Paraguai quatro barras de sedimento (BS01, BS02, BS03, BS04) na margem convexa, sua origem está associada à perda da capacidade de transportar, devido o decréscimo de energia do fluxo na margem convexa, o surgimento dessas feições está relacionado através de processos de deposito por acreção lateral (figura 2 e tabela 1).

Houve a formação de barras de sedimento (BS05, BS06) no novo canal (NC03) (figura 2). Os processos de formação dessas feições ocorreram devido ao regime hídrico, mais especificamente pela variação no nível da água e da vazão, uma vez que no período das cheias há o transporte de agua e sedimentos do rio para a planície. Nos períodos das cheias o canal (NC2) transporta sedimentos para o canal secundário (NC03), na maior parte do ano esse não tendo a capacidade de transporte acumula os sedimentos em seu leito, dessa forma ocorre à deposição dos sedimentos.

Tabela 01 - Áreas de baías, lagoas e canais secundários em $\mathrm{Km}^{2}$ localizadas no rio Paraguai entre o Furado da Palha e o Sadao no município de Cáceres-MT

\begin{tabular}{c|c|c} 
& & \\
Feições & Área $\mathrm{km}^{2}$ & Área $\mathrm{km}^{2}$ \\
& 1975 & 2016 \\
\hline Baía 01 & 0,008 & 0,003 \\
\hline Baía 02 & 0,029 & 0,013
\end{tabular}




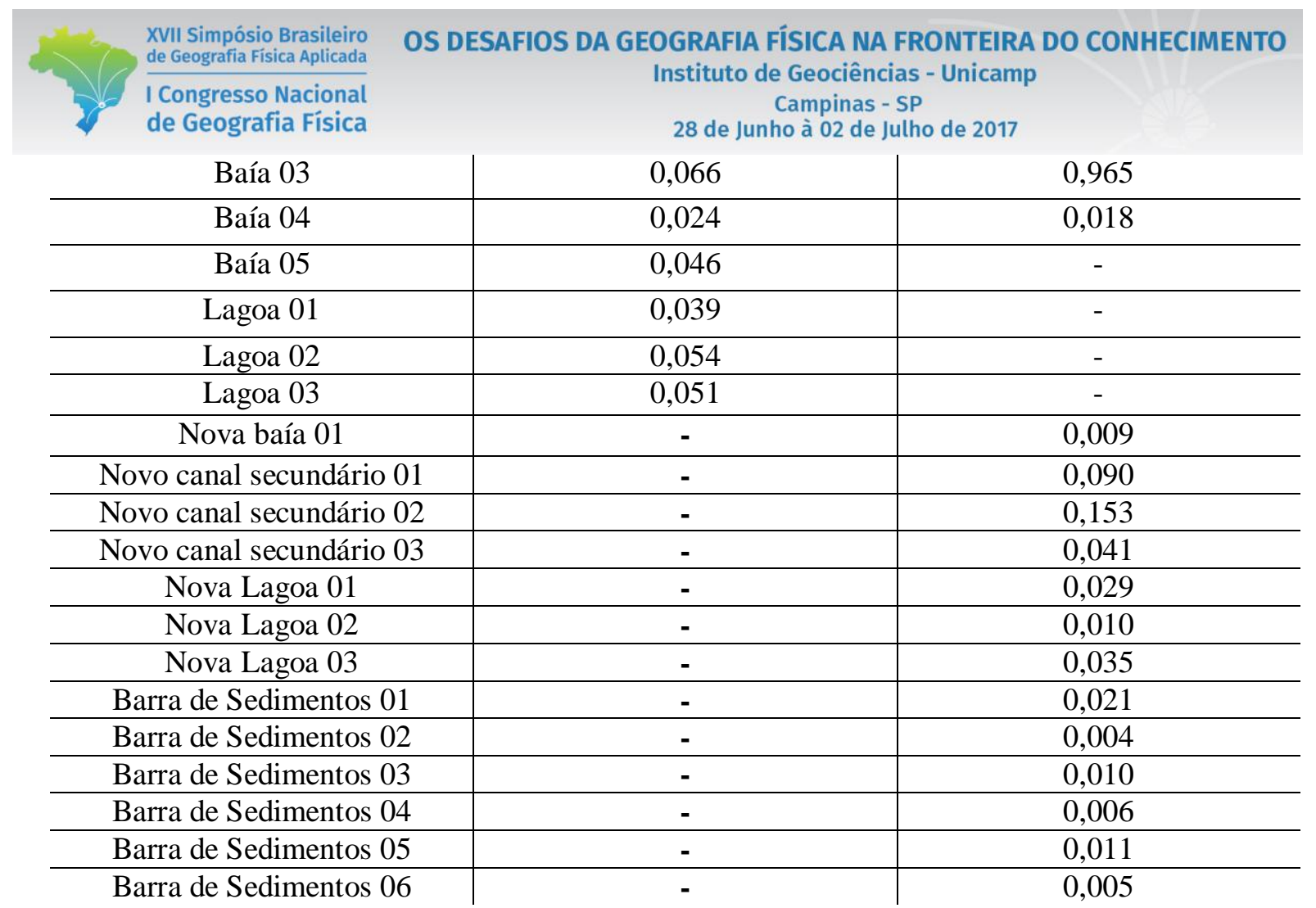

\section{CONSIDERAÇÕES FINAIS}

A análise do mapa de evolução espaço-temporal no trecho entre a baía da Palha e o Sadao no corredor fluvial do rio Paraguai, nos anos de 1975 e 2016 mostrou algumas mudanças: desaparecimento de algumas feições (baías e lagoas) e surgimento de outras (canais secundários e barras de sedimentos) e houve também alterações dimensionais dessas feições. Os fatores que contribuem para as mudanças morfológicas ao longo dos anos estão relacionados à dinâmica exercida pelo próprio sistema fluvial do rio Paraguai, condicionados aos períodos de seca e cheia.

\section{BIBLIOGRAFIA}

Allen, J. R. L. Studies in fluviatile sedimentation: six cyclotems from the Lawer Old Red Sandstone, AngloWesh Basin. Sedimentology, 3, p. 163-198. 1964.

BARROS, A. M.; SILVA, R. H.; CARDOSO, O. R. F. A.; FREIRE, F. A.; SOUZA JUNIOR, J. J.; RIVETTI, M.; LUZ, D. S.; PALMEIRA, R. C. B.; TASSINARI, C. C. G. Geologia. In: BRASIL. Ministério das Minas e Energia. Secretaria Geral. Projeto RADAMBRASIL. Folha SD. 21 - Cuiabá; Geologia, Geomorfologia, Pedologia, Vegetação e Uso potencial da terra. Rio de Janeiro, 1982. p. 25 -192.

BINDANDI, N. M. Evolução da navegação, morfologia e sedimentação no rio Paraguai no município de Cáceres, Mato Grosso, Brasil. 2014. 125 f. Dissertação(Mestrado em Ciências Ambientais) - Instituto de Ciências Naturais e Tecnológicas,Universidade do Estado de Mato Grosso - UNEMAT, Cáceres - MT, 2014.

BÜHLER, B. F. Qualidade da água e aspectos sedimentares da bacia hidrográfica do rio Paraguai no trecho situado entre a baía do Iate e a região do Sadao, município de Cáceres (MT), sob os enfoques quantitativos e 


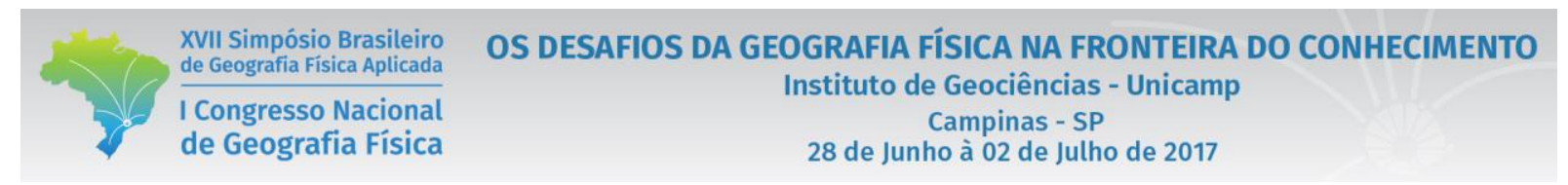

perceptivos. 2011. 140 f. Dissertação (Mestrado em Ciências Ambientais) - Instituto de Ciências Naturais e Tecnológicas, Universidade do Estado de Mato Grosso - UNEMAT, Cáceres - MT, 2011.

CHRISTOFOLETTI, A. Geomorfologia Fluvial. São Paulo: Editora. Edgard Blücher. 1981.

CLARKE, R. T; TUCCI, C. E. M; COLLIISHONN, W. Variabilidade Temporal no Regime Hidrológico da Bacia do Rio Paraguai. RBRH - Revista Brasileira de Recursos Hídricos Volume 8 n.1 Jan/Mar 2003, p. 201-211.

LEOPOLD, L.B.; WOLMAN, M.G.; River meanders. Bull. Geol. Soc. Am., 71: p. 769 -794, 1960.

OLIVEIRA, V. A.; AMARAL FILHO, Z. P.; VIEIRA, P. C. Pedologia: levantamento exploratório de solos. In: BRASIL. Ministério das Minas e Energia. Secretaria Geral. Projeto RADAMBRASIL. Folha SD. 21 - Cuiabá: Geologia, Geomorfologia, Pedologia, Vegetação e Uso potencial da terra. Rio de Janeiro, 1982. p. 257 - 400.

ROCHA, P. C. Geomorfologia e Áreas Inundáveis na Planície Fluvial do Alto rio Paraná. Rev. Geogr. Acadêmica v.5, n.1, 2011, p. 98-117.

SANTOS, M. L.; FERNANDEZ, O. V. Q.; STEVAUX, J. C.; Aspectos Morfogenéticos das Barras do Canal Rio Paraná, Trecho de Porto Rico, PR. Boletim de Geografia -UEM- Ano 10- número 01. Ano 1992, p. 11-24.

SILVA, A.; FILHO, S. E. E.; NEVES, S. A .M, S,; Erosão marginal e sedimentação no rio Paraguai no município de Cáceres (MT). Revista Brasileira de Geociências 41(1): p. 76-84, março de 2011.

SILVA, E. S. F. Dinâmica fluvial do rio Paraguai no segmento entre furado do Touro e passagem Velha, Cáceres- Mato Grosso, Brasil. 2012. 113 f. Dissertação(Mestrado em Ciências Ambientais) - Instituto de Ciências Naturais e Tecnológicas, Universidade do Estado de Mato Grosso - UNEMAT, Cáceres - MT, 2012.

SILVA, E. S. F.; SOUZA, C. A.; LEANDRO, G. R. S.; ANDRADE, L. N.P.S.; GABIATI, C.; Evolução das feições morfológicas do rio Paraguai no Pantanal de Cáceres - Mato Grosso. Revista Brasileira de Geomorfologia, v.13, n.4, (Out-Dez) p.435-442, 2012.

SOUZA, C. A. Dinâmica do corredor fluvial do rio Paraguai entre a cidade de Cáceres e a Estação Ecológica da ilha de Taiamã-MT. 2004. 173 f. Tese (Doutorado em Geografia) - Centro de Ciências Matemáticas e da Natureza, Universidade Federal do Rio de Janeiro - UFRJ, Rio de Janeiro, 2004.

SOUZA, C. A.; SOUZA, J. B.; CABRAL, I. L. L. PIERANGELI, M. A. P.; MIRANDOLA, P. H.; Ambiente do corredor fluvial do rio Paraguai entre a cidade de Cáceres e a Estação Ecológica da Ilha de Taimã. (Org.). In: SOUZA, C. A. Bacia Hidrografica do rio Paraguai - MT: Dinâmica das águas, uso e ocupação ambiental. São Carlos. Editora Cubo, 2012, p. 23-37.

SOUZA, C. A.; VENDRAMINI, W. J.; SOUZA, M. A.; Assoreamento Na Baía do Sadao no rio Paraguai Cáceres Mato Grosso. Cadernos de Geociências, v. 9, n. 2, novembro 2012, 85-93.

SUGUIO, K.; BIGARELLA, J.J. Ambientes Fluviais. Florianópolis: Editora da UFSC e Editora da UFPR, 1990, p. 183. 